\title{
Social class and coronary heart disease
}

\author{
GEOFFREY ROSE, M G MARMOT* \\ From the Department of Medical Statistics and Epidemiology, London School of Hygiene and Tropical \\ Medicine, London
}

SUMMARY Over the past 40 years in England and Wales the rise in mortality from coronary heart disease has continued unabated among working-class men, whereas among professional men the rate has changed little for the past 20 years. As a result it is now 26 per cent higher in social class $\mathrm{V}$ compared with social class $\mathrm{I}$. The difference in women is larger $(+152 \%)$, and it has been present for at least 40 years.

The social class gradient for men was confirmed in a survey of 17530 London civil servants aged between 40 and 64 (the Whitehall Study). When men in the lowest employment grade were compared with those in the top (administrative) grade, the age-adjusted prevalence rate was 53 per cent higher for angina, 77 per cent higher for ischaemic-type electrocardiographic abnormalities, and 75 per cent higher for the prevalence of electrocardiographic abnormality among men with angina. At follow-up, the seven-and-a-half year coronary mortality was 3.6 times higher in the lowest than in the top grade.

This social class difference was partly explained by known coronary risk factors: men in the lower grades smoked more and exercised less, they were shorter and more overweight, and they had higher blood pressures and lower levels of glucose tolerance. Most of the difference, however, remains unexplained. It seems that there are major risk factors yet to be identified, and that these may throw light on how it is possible for members of a highly-placed social group to have a relatively low risk of coronary heart disease.

In his Textbook of the practice of medicine the cardiologist Frederick Price ${ }^{1}$ wrote in 1941, "Angina pectoris ... is much more common in those classes of society who are subject to excessive mental or emotional stress or strain, being relatively uncommon in those whose occupation is of a manual character". In this paper we shall consider whether he was right, how the situation may have changed, and what underlying factors may explain the association of social class with coronary heart disease. $\dagger$

\section{Historical background}

Price's view was supported by the available statistics of his day. In $1931,{ }^{2}$ the age-adjusted rate for deaths attributed to angina pectoris was 237 per cent of the national average for men in social class $I$,

* Address: London School of Hygiene and Tropical Medicine, Keppel Street, London WC1E 7HT.

† Social class definitions in England and Wales:

I $=$ Professional

II = Managerial, senior clerical

III $=$ Skilled

IV $=$ Semi-skilled

$\mathrm{V}=$ Unskilled. compared with 67 per cent in social class V. In line with the then current medical beliefs, however, the label "angina" was perhaps more likely to be recorded when a businessman died of heart disease; for a working man some vaguer term such as "myocardial degeneration" might well have been preferred.

Table 1 shows how diagnostic usage has changed over a period of 40 years. In 1931 the less precise descriptions of non-valvular heart disease were usual, especially for patients at the lower end of the social spectrum. Nowadays not only are specific

Table 1 Changing relative frequency of various diagnostic labels in deaths from heart diseases according to social class (men, ages 35 to 64, England and Wales), expressed as proportions of all deaths in period attributed to non-valvular heart disease

\begin{tabular}{lllll}
\hline Year & \multicolumn{2}{l}{$\begin{array}{l}\text { Angina, } \\
(\%)\end{array}$} & $M I, I H D$ & \multicolumn{2}{l}{$\begin{array}{l}\text { Other myocardial } \\
\text { diseases }(\%)\end{array}$} \\
\cline { 2 - 5 } & $I+I I$ & $I V+V$ & $I+I I$ & $I V+V$ \\
\hline 1931 & 31 & 13 & 69 & 87 \\
1951 & 73 & 62 & 27 & 38 \\
1961 & 87 & 84 & 13 & 16 \\
1971 & 92 & 90 & 8 & 11 \\
\hline
\end{tabular}


terms the rule, but they are used regardless of social class. In examining historical trends, especially in relation to social class, it is clearly wise to employ some broader category such as "all nonvalvular heart disease". This assumes that coronary heart disease constitutes the bulk of this broad category, that it has largely determined its variations, and that "myocardial degeneration" was usually a misnomer for coronary heart disease. These assumptions, though seemingly reasonable, are not testable retrospectively.

The definititions and composition of the social classes have also changed. In particular, social class $\mathrm{V}$ has shrunk and many of its members have been promoted to class IV; as a result the residue of class $\mathrm{V}$ is now relatively more disadvantaged than the average of their predecessors, and comparisons across time are fallacious. Similarly, class I has grown by the increase of professional jobs. As with disease labels, in examining trends it is necessary to group together into broader categories.

Fig. 1 shows the changing social class pattern of mortality from non-valvular heart disease over the past $\mathbf{4 0}$ years among middle-aged men and married women in England and Wales. In 1931 mortality among men was indeed greatest at the higher social levels, though not by nearly so much as current medical opinion supposed. At all social levels the situation worsened over the next 20 years. After 1951 , however, the death rate in social classes I and II stabilised, at least for a time, whereas in classes IV and V the deterioration accelerated. As a result the social class rates crossed during the 1950s,

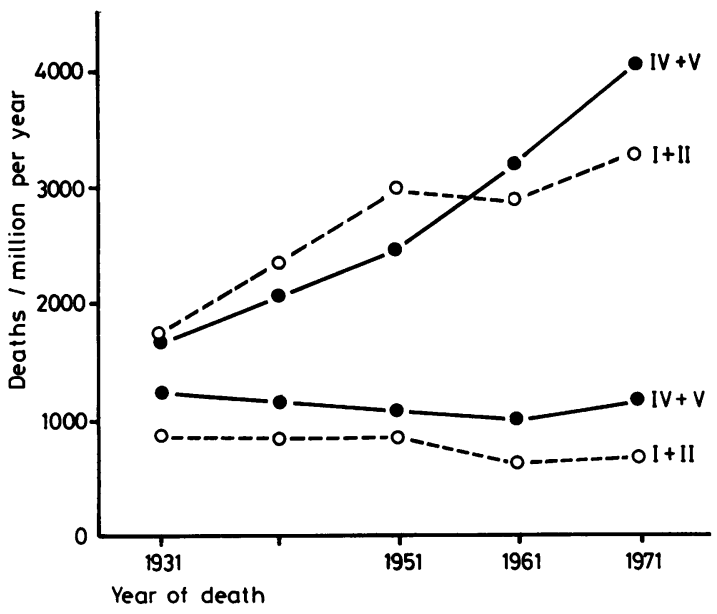

Fig. 1 Mortality from non-valvular heart disease during 1931-71 in men (upper pair of lines) and married women (lower pair of lines) in England and Wales, ages 35 to 64 , according to social class $(I+I I$ versus $I V+V) . .^{2-6}$ reversing the differential of earlier years and giving the higher classes a sizeable advantage. By 1971 the age-adjusted mortality for myocardial infarction (ICD 410-414, 8th revision, men 15 to 64) was 26 per cent higher in social class $V$ relative to class $I$.

The trends among women have been quite different. Throughout the whole period since 1931 "non-valvular heart disease" (and by inference coronary heart disease, too) has predominantly affected the working classes. At all social levels rates were falling up till 1961, but they have since risen (especially in classes IV and V). Overall, the social class gap in mortality among women has not changed a lot during $\mathbf{4 0}$ years; in relative terms it has throughout been much larger than in men. Age-adjusted mortality from coronary heart disease (ICD 410 to 414) among married women under age 65 in 1971 was 152 per cent higher in social class $\mathrm{V}$ relative to $\mathrm{I}$.

\section{Limitations of national data}

National statistics may serve to identify phenomena, but they are generally weak as a means of quantifying and explaining them. Each of the five national social classes is itself heterogeneous; this implies that the true differential in coronary heart disease could be even larger than appears in the Registrar General's statistics, since misclassifications tend to dilute true effects. Moreover, conclusions based on death certificates call for confirmation by clinical examination, and to assess their prognostic significance requires follow-up studies.

It is, however, in the attempt to explain disease phenomena that the limitations of national data are most evident. In an earlier report ${ }^{6}$ we tried to relate these changes in the social class patterns of heart disease to concurrent changes in exposure to possible causes. Unfortunately, it is hard to obtain relevant national data (except in the case of smoking), and in addition these cannot be related to personal characteristics or behaviour. To obtain such information on individuals requires a special survey. Such a study was set up by our group in 1968 under the direction of the late D D Reid.

\section{Whitehall Study: Subjects and methods}

A total of 18403 male civil servants aged between 40 and 64 were examined for symptoms, signs, and risk factors related to cardiorespiratory disease. ${ }^{78}$ The examination included the assessment of angina of effort by standard questionnaire, and an electrocardiogram classified by Minnesota Code criteria. The electrocardiogram was designated as positive for ischaemic-type changes if it showed Q/QS items 
(codes 1.1-3), ST/T items (codes 4.1-4 or 5.1-3), or left bundle-branch block (code 7.1). The files of over 99 per cent of participants were flagged at the National Health Service Central Registry, thus providing a virtually complete follow-up of mortality. Results are presented here for the first seven-and-a-half years, during which time 462 deaths were attributed to coronary heart disease (ICD 410-414).

Civil servants can be grouped according to their employment status into five main grades, namely, administrative, professional, executive, clerical, and "other". The "other" grade was the lowest in status, comprising mainly unskilled manual workers. For our analysis we combined the professional and executive grades, since they were of overlapping status and similar health experience. Eight hundred and seventy-three men from the Diplomatic Service and British Council were excluded, because their employment status was classified differently; this left 17530 for the present analysis (administrative 960 , professional/executive 12177 , clerical 2768 , and other grades 1625). Age-adjustment was carried out by the direct method, using the total study population as the standard.

\section{PREVALENCE RESULTS}

Table 2 shows the prevalence of angina and ischaemic-type electrocardiographic abnormalities according to employment grade. For each there is a highly significant trend, but it is stronger and more consistent for electrocardiographic abnormalities than for angina. In the lowest grade the rate for electrocardiographic abnormalities is 177 per cent of that for the top grade. Equally strong is the gradient in the association of angina with electrocardiographic abnormality: the lower the grade, the more likely it is that angina will be accompanied by electrocardiographic abnormality.

Table 2 Prevalence rates (age-adjusted) of angina and ischaemic-type electrocardiographic abnormalities, and association of angina with electrocardiographic abnormality, according to employment grade (ages 40 to 64 )

\begin{tabular}{llll}
\hline Grade & \multicolumn{2}{l}{ Prevalence percentage } & $\begin{array}{l}\text { Percentage of angina } \\
\text { with positive } \\
\text { electrocardiogram }\end{array}$ \\
\cline { 2 - 3 } & Angina & $\begin{array}{l}\text { Positive } \\
\text { electrocardiogram }\end{array}$ \\
\hline $\begin{array}{l}\text { Administrative } \\
\text { Professional/ } \\
\text { executive }\end{array}$ & 3.41 & 4.63 & 10.0 \\
$\begin{array}{l}\text { Clerical } \\
\text { Other }\end{array}$ & 4.77 & 5.97 & 13.6 \\
\hline & 5.24 & 6.82 & 16.5 \\
\hline
\end{tabular}

MORTALITY

Fig. 2 plots the probability of death from coronary

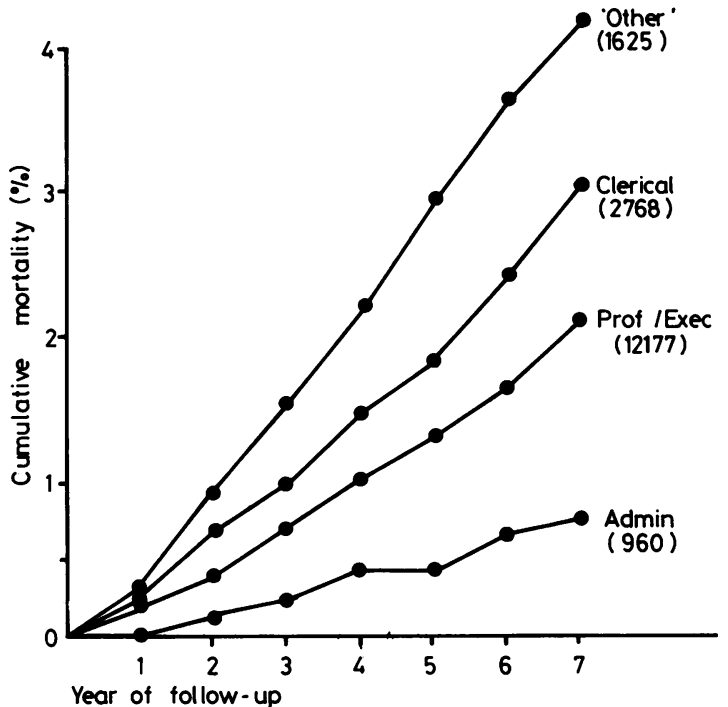

Fig. 2 Cumulative age-adjusted mortality from coronary heart disease according to employment grade and year of follow-up (numbers of subjects in parentheses).

heart disease in each year of follow-up (conditional on the man avoiding death from other causes). Rates for the different employment grades begin to diverge during the first year, and thereafter the gaps grow steadily wider. These differentials were more or less consistent within each age group. ${ }^{9}$

Table 3 Age-adjusted seven-and-a-half year mortality from coronary heart disease according to employment grade, including risk of death from coronary heart disease in men with "suspected ischaemia" at initial examination

\begin{tabular}{|c|c|c|c|}
\hline \multirow{2}{*}{ Grade } & \multicolumn{3}{|c|}{$\begin{array}{l}\text { Percentage dying of coronary heart } \\
\text { disease (no. of deaths) }\end{array}$} \\
\hline & $A l l$ men & \multicolumn{2}{|c|}{$\begin{array}{l}\text { "Suspected } \\
\text { ischaemia" }\end{array}$} \\
\hline $\begin{array}{l}\text { Administrative } \\
\text { Professional/executive } \\
\text { Clerical } \\
\text { Other }\end{array}$ & $\begin{array}{ll}1.07 & (9) \\
2.29 & (255) \\
3.36 & (111) \\
3.89 & (87)\end{array}$ & $\begin{array}{l}4 \cdot 3 \\
5 \cdot 8 \\
7 \cdot 7 \\
9 \cdot 0\end{array}$ & $\begin{array}{l}(5) \\
(111) \\
(45) \\
(38)\end{array}$ \\
\hline
\end{tabular}

Table 3 presents age-adjusted seven-and-a-half year coronary mortality rates. Among the 960 men in the top (administrative) grade, only nine died of coronary heart disease, giving the remarkably low frequency of one death per 800 men per year. By contrast there were 87 deaths among 1625 men in the lowest grade of employment. This was a somewhat older group, but even after age adjustment their rate was still 3.6 times that in the top grade.

At entry to the study men were classed as having 
"suspected ischaemia" if they gave a history of chest pain suggesting either angina or previous myocardial infarction, or if the electrocardiogram suggested ischaemia. Table 3 shows the large increase in risk of death associated with these findings. The relative increase is more or less independent of employment grade, and as a result the presence of "suspected ischaemia" in the lowest grade identified a group that was at particularly high risk. In men without "suspected ischaemia", employment grade still predicted mortality strongly.

Age-adjusted mortality rates were also calculated for all causes other than coronary heart disease. The trend over the four employment grades had the same slope as that for coronary heart disease. This indicates both that the latter can hardly be a result of diagnostic transfers, and also that the phenomenon of social class mortality differences is not specific to heart disease.

\section{CORONARY RISK FACTORS}

Table 4 compares the employment grades with respect to some coronary risk factors. (The extent to which these factors predicted coronary mortality in the Whitehall Study has been reported already. ${ }^{8}$ ) much less commonly in the lower grades.

Height was significantly related to grade, a height of 6 feet $(1.83 \mathrm{~m})$ or more being less than half as common in the lowest grade as among administrators. Coronary mortality was also strongly related to shortness, being 54 per cent greater in men whose height was $5 \mathrm{ft} 6$ in $(1.68 \mathrm{~m})$ or less than in those over $6 \mathrm{ft}(1.83 \mathrm{~m}) .{ }^{9}$ Differences between grades in mean "body mass index" (weight/height ${ }^{2}$ ) were less than in height, but there was a considerable excess in the lower grades of more severe degrees of overweight.

Systolic blood pressure showed a consistent trend across the employment grades, averaging $4.2 \mathrm{mmHg}$ ( 0.2 standard deviations) less among men in the top grade. This would correspond to a reduction of approximately 13 per cent in the estimated coronary mortality. For plasma total cholesterol level the trend was in the opposite direction, with the difference between the top and bottom grades averaging $0.23 \mathrm{mmol} / \mathrm{l}$ (again, about 0.2 standard deviations). Diet was studied in a random 10 per cent sample of participants, using three-day diary records. Differences between employment grades were small, the most significant statistically being a

Table 4 Major risk factors and employment grade: age-adjusted mean values ( $\pm S E$ ), and proportion with "elevated" values

\begin{tabular}{|c|c|c|c|c|}
\hline \multirow{2}{*}{ Variable } & \multicolumn{4}{|l|}{ Grade } \\
\hline & Administrative & Professional/executive & Clerical & Other \\
\hline $\begin{array}{l}\text { Cigarettes/day } \\
\% \text { Smokers }\end{array}$ & $\begin{array}{ll}4 \cdot 2 & ( \pm 0 \cdot 2) \\
29 & \end{array}$ & $\begin{array}{l}6 \cdot 0 \quad( \pm 0 \cdot 1) \\
37\end{array}$ & $\begin{array}{ll}8 \cdot 5 & ( \pm 0 \cdot 2) \\
53 & \end{array}$ & $\begin{array}{l}10 \cdot 1 \quad( \pm 0 \cdot 3) \\
61 \\
14\end{array}$ \\
\hline $\begin{array}{l}\text { Height }(m) \\
\quad \% \geqslant 1.83 \mathrm{~m}(6 \mathrm{ft})\end{array}$ & ${ }_{21}^{1.78}( \pm 0.0020)$ & $13 \cdot 76 \quad( \pm 0 \cdot 0005)$ & $1 \cdot 74 \quad( \pm 0.0013)$ & ${ }_{9}^{1.73} \quad( \pm 0.0023)$ \\
\hline $\begin{array}{c}\text { Weight } / \text { height } \\
\% \geqslant 28 \mathrm{~kg} / \mathrm{m}^{2}\end{array}$ & $\begin{array}{l}24.5 \quad( \pm 0.09) \\
10\end{array}$ & $\begin{array}{l}24 \cdot 8 \quad( \pm 0.03) \\
12\end{array}$ & $\begin{array}{l}24 \cdot 6 \quad( \pm 0.07) \\
14\end{array}$ & $\begin{array}{l}25 \cdot 0 \quad( \pm 0 \cdot 10) \\
17\end{array}$ \\
\hline $\begin{array}{l}\text { Systolic BP (mmHg) } \\
\% \geqslant 160 \mathrm{mmHg}\end{array}$ & $\begin{array}{c}133.7 \\
11\end{array}( \pm 0.67)$ & $\begin{array}{c}136 \cdot 0 \\
12\end{array}( \pm 0 \cdot 19)$ & $\underset{14}{136 \cdot 8}( \pm 0 \cdot 42)$ & $\begin{array}{c}137.9 \\
16\end{array}( \pm 0.64)$ \\
\hline Plasma cholesterol (mmol/l) & $5 \cdot 19( \pm 0.044)$ & $5 \cdot 13 \quad( \pm 0.011)$ & $5.08 \quad( \pm 0.26)$ & $4.96 \quad( \pm 0.038)$ \\
\hline Blood glucose ${ }^{\star}(\mathrm{mmol} / \mathrm{l})$ & $4 \cdot 17 \quad( \pm 0.026)$ & $4 \cdot 18 \quad( \pm 0.009)$ & $4.26 \quad( \pm 0.022)$ & $4.31 \quad( \pm 0.046)$ \\
\hline
\end{tabular}

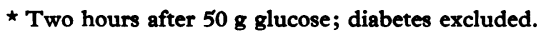

Men in the lowest grade were twice as likely to smoke cigarettes as those in the top grade. The difference was even larger for average cigarette consumption, since the smokers in the lower grades tended to smoke more heavily. They also tended to prefer brands with a higher tar and nicotine yield; but this difference, though it influences cough and sputum production, ${ }^{10}$ does not seem to increase the risk of coronary heart disease.

Physical activity at work was light in all grades, especially in the higher grades. By contrast, physically active leisure-time activities were reported tendency to lower intake of sucrose by men in the higher grades.

Glucose tolerance was estimated by a single measurement of blood sugar two hours after a $50 \mathrm{~g}$ glucose load; this was administered after an overnight fast. Blood sugar levels tended to be higher among men in the lower grades; but the difference between the highest and lowest grades was small ( 0.05 standard deviations), and it explained very little of the observed difference in coronary risk.

In order to assess the combined effect of these risk factors we undertook a multivariate analysis, 
using the multiple logistic method. (This produces slightly different risk estimates from both the direct method of standardisation and the life-table method used earlier in the paper.) In Fig. 3 the mortality rate for administrators is taken as 1.0 ; the relative risks for the professional/executive, clerical, and "other" grades are then $2 \cdot 1,3 \cdot 2$, and $4 \cdot 0$, respectively. The shaded parts of each bar show how much of the risk difference for that grade can be explained statistically by its difference from the administrators with respect to each risk factor, independent of the effect of the other factors (including age). The unshaded upper part of each bar shows the discrepancy between what can be "explained" and what remains unexplained even after taking account of all the factors we measured (that is age, smoking, blood pressure, height, overweight, leisure-time activity, and glucose tolerance; plasma cholesterol was also included, but showed a reversed risk gradient).

\section{Discussion}

Experience in Third World countries shows that where poverty is prevalent, coronary heart disease is rare. While it is true that in India and parts of Africa, for example, the disease is increasing, yet it

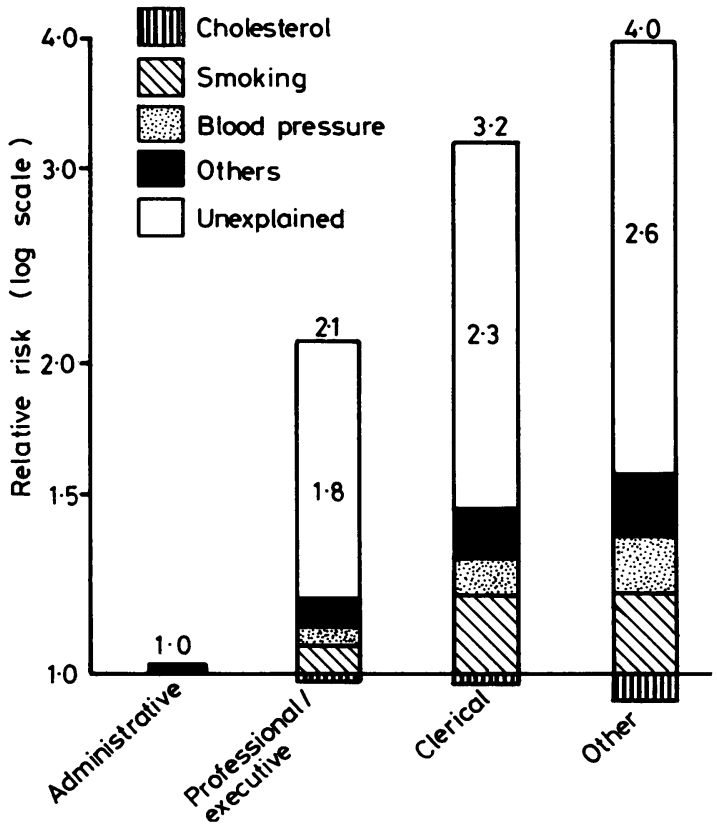

Fig. 3 Relative risk of death from coronary heart disease according to employment grade, and proportions of differences that can be explained statistically by various risk factors. is still seen largely in the cities, among professional men and clerks rather than among artisans and peasants. The same may have been true at one time in Western countries, as doctors at the time firmly believed. National data take us back only to 1931 . It seems that by that time in Britain there was still a true excess among professional men over artisans, but it was small: most of the large apparent excess probably resulted from diagnostic transfers.

Since 1931 the mortality trend for men in social classes IV and V has been consistently adverse, at least up to 1971 (the latest year for which occupationally-related rates are available). For men in social classes I and II the position from 1951 to 1971 had more or less stabilised, but they had not yet shared in the considerable decline enjoyed by male British doctors. ${ }^{11}$ As a result, coronary heart disease (like all the other leading causes of death) now bears most heavily on men in the working classes. For women this has been the case at least back to the 1920 s.

Our survey findings in the Whitehall Study confirm a large excess of coronary heart disease among men in the lower employment grades, both for prevalence and mortality. In America a survey set up in 1954 disclosed approximate equality, in both prevalence and incidence rates, between strata of a Chicago utility company. ${ }^{12}$ Later studies in America and elsewhere have tended, however, to show the same direction of difference as in our study. ${ }^{13}$

Our most striking finding was the size of this social class effect: a man's employment status was a stronger predictor of his risk of dying from coronary heart disease than any of the more familiar risk factors. A small part of this difference could have resulted from selection of unfit men into (in particular) the lowest grade of employment. But there are generally no pre-employment medical examinations for civil servants; the differential was present even among men who at entry to the study were symptom-free; it was as strong in the late as in the early follow-up period (Fig. 2), and it was not confined to the two lower grades (where such medical selection might be expected). We conclude that it is substantially real, and therefore calls for explanation.

London civil servants as a whole had a coronary mortality rate close to the national average. It is possible, but it seems unlikely, that their individual exposures to the causes of this disease are exceptionally unequal. A more probable explanation of the steep mortality gradient is simply that the men are better classified into more homogeneous groups than in the national statistics; there is less error to cloud true effects. If this is the case, then the same 
large differentials exist in the general population, but they are concealed by misclassifications.

The multivariate analysis (Fig. 3) showed that some of the differential could be explained statistically in terms of the lower levels of (particularly) smoking and blood pressure among men in higher employment grades. Though plasma total cholesterol level was a strong predictor of coronary mortality within each employment grade, yet it did not help to explain the difference between the grades; in fact, it tended to reduce that difference. Thus most of the intergrade phenomenon remains unexplained.

\section{Directions for research}

Our results are based on single measurements made under arbitrarily standardised conditions, whereas arteries are exposed to all the fluctuations in pressure and biochemistry which occur during daily life. It could be, for example, that men in the lower employment grades are particularly exposed, at work or at home, to physical or emotional stimuli of a kind which increases their blood pressure at those times.

Differences in smoking behaviour seem clearly to be important. But no one yet knows what constituent of cigarette smoke causes or aggravates coronary heart disease, and a simple measure of the total amount smoked might misestimate the true effect of smoking. Perhaps, for example, smokers in the lower employment grades smoke brands of cigarettes which produce more carbon monoxide.

Coronary atherosclerosis begins to develop early in adult life, but in this study our search for causes began late. It may be that the social class pattern of adult disease is an outcome of earlier differences in childhood nutrition, perhaps in lipid or salt intake. That would make research difficult, for today's children may not mirror the childhood of today's adults. The difference in height which we observed, and which was predictive of coronary risk, presumably indicates a difference in either genetic constitution or childhood nutrition.

The "conventional" risk factors explain a great deal about the occurrence of coronary heart disease, but they also leave a great deal unexplained. It remains to be seen how much of the gap in our knowledge can be filled by other factors which are now being studied, including high-density lipoprotein levels, ${ }^{14}$ haemostatic factors, ${ }^{15}$ dietary polyunsaturated fatty acids ${ }^{16}{ }^{17}$ or fibre, ${ }^{18}$ or stress. Any or all of these might throw light on the unexplained differences in risk between the social classes. Perhaps most useful of all would be to know whether there are differences in atherosclerosis, or whether we should be looking for differences in the determinants of thrombosis and myocardial disorder.

There may be other major causes of coronary heart disease not yet suspected. These could include genetic factors, acting independently of familiar risk factors. The height differences between the different employment grades, which are strongly related to coronary risk, must be indicating differences either in childhood nutrition or in genetic constitution. For centuries the social classes have been inbreeding and selectively breeding, and it would be remarkable if they were not by now genetically different. Unfortunately, we are short of suitable markers of genetic susceptibility to coronary disease.

This great concentration of heart disease among working-class men and women might not be wholly the result of specific causes: in the Whitehall Study, and in the country as a whole, the same concentration is seen for most of the other leading causes of death. Possibly some general biological factor, genetically or nutritionally determined, may nonspecifically enhance the individual's susceptibility to a variety of diseases. There is a precedent for such a factor in "male sex", which from fetal life onwards carries an enhanced risk of death from many causes, including coronary heart disease.

\section{Conclusion}

In at least one reasonably affluent section of the community-the administrative grade of the civil service-coronary heart disease is, if not rare, at least uncommon by Western standards. One factor which contributes to their fortunate position is clear and can be copied by others; namely, they smoke but little. Other important parts of the explanation remain currently unknown but may be illuminated by further research. Meanwhile, it is at least seen that affluent urban living does not necessarily carry a high risk of death from coronary heart disease.

Dr M Marmot is supported in part by a British Heart Foundation grant.

We thank the Civil Service Department Medical Advisory Service for their collaboration.

\section{References}

1 Price FW, ed. A textbook of the practice of medicine. 6th ed. London: Oxford University Press, $1941: 981$.

2 Registrar General. Decennial supplement, occupational mortality, England and Wales 1931. London: HMSO, 1938. 
3 Registrar General. Decennial supplement, occupational mortality, England and Wales 1951. London: HMSO, 1954.

4 Registrar General. Decennial supplement, occupational mortality, England and Wales 1961. London: HMSO, 1971.

5 Office of Population Censuses and Surveys. Occupational mortality, The Registrar General's decennial supplement for England and Wales 1970-72. Series DS No. 1. London: HMSO, 1978.

6 Marmot MG, Adelstein AM, Robinson N, Rose GA. Changing social-class distribution of heart disease. Br Med f 1978; 2: 1109-12.

7 Rose G, McCartney P, Reid DD. Self-administration of a questionnaire on chest pain and intermittent claudication. $\mathrm{Br}$ F Prev Soc Med 1977; 31: 42-8.

8 Reid DD, Hamilton PJS, McCartney P, Rose G, Jarrett RJ, Keen H. Smoking and other risk factors for coronary heart-disease in British civil servants. Lancet 1976; 2: 979-84.

9 Marmot MG, Rose G, Shipley M, Hamilton PJS. Employment grade and coronary heart disease in British civil servants. $\mathcal{F}$ Epidemiol Community Health 1978; 32: 244-9.

10 Higenbottam T, Clark TJH, Shipley MJ, Rose G. Lung function and symptoms of cigarette smokers related to tar yield and number of cigarettes smoked. Lancet 1980; 1 : 409-12.
11 Doll R, Peto R. Mortality in relation to smoking: 20 years' observations on male British doctors. Br Med f 1976; 2: 1525-36.

12 Stamler J, Lindberg HA, Berkson DM, Shaffer A, Miller W, Poindexter A. Prevalence and incidence of coronary heart disease in strata of the labor force of a Chicago industrial corporation. $f$ Chronic Dis 1960; 11: 405-20.

13 Antonovsky A. Social class and the major cardiovascular diseases. F Chronic Dis 1968; 21: 65-106.

14 Miller GJ, Miller NE. Plasma-high-density lipoprotein concentration and development of ischaemic heart-disease. Lancet 1975; 1 : 16-9.

15 Meade TW, North WRS, Chakrabarti R, Haines AP, Stirling Y. Population-based distributions of haemostatic variables. $\mathrm{Br}$ Med Bull 1977; 33: 283-8.

16 Logan RL, Riemersma RA, Thomson M, et al. Risk factors for ischaemic heart-disease in normal men aged 40. Edinburgh-Stockholm study. Lancet 1978; 1: 949-55.

17 Sinclair H. Dietary fats and coronary heart-disease. Lancet 1980; 1 : 414-5.

18 Morris JN, Marr JW, Clayton DG. Diet and heart: a postscript. $\mathrm{Br}$ Med $\mathcal{Y} 1977$; 2: 1307-14.

Requests for reprints to Professor G Rose, London School of Hygiene and Tropical Medicine, Keppel Street, Gower Street, London WC1E 7HT. 